\title{
Research on Supply Chain Service Innovation Based on B2C E-Commerce Platform in Information Ecology
}

\author{
He Ping, Yu Hongjian \\ Hangzhou Normal University, Hangzhou, Zhejiang, China, 311121
}

Keywords: supply chain; innovation; B2C e-commerce platform

\begin{abstract}
As an emerging field, B2C e-commerce has developed rapidly in recent years. However, due to capital constraints, development has encountered many bottlenecks. As a bank's innovative business, supply chain finance has been widely used in traditional industries to solve the problem of innovative financing for SMEs. However, there are few research literatures on the application of supply chain finance in e-commerce, especially in the field of B2C e-commerce at home and abroad. Applying supply chain finance to B2C e-commerce, using online order innovation financing, innovative financing of online warehouse receipts, and e-commerce guarantees for innovative financing, and analyzing and controlling its risks, can help integrate and optimize the flow of B2C e-commerce funds, logistics and information flow, improve the liquidity of its assets, accelerate the turnover of the company's trade, and improve the company's operating capabilities.
\end{abstract}

\section{Introduction}

Supply chain innovation financing refers to the bank's assessment of relevant companies in the supply chain as a whole, and the design of innovative financing solutions, the use of multiple financial portfolios, and innovative financing of companies with funding needs in the supply chain. The relevant SMEs in the supply chain receive innovative financing support to solve the problem of unbalanced distribution of funds on the supply chain and enhance the competitiveness of the entire supply chain.

\section{Advantages of B2cC E-commerce Platform}

\subsection{Adequate inventory.}

Although compared with traditional enterprises, B2C e-commerce supply and marketing channels are relatively special, do not need to sell stores, and e-commerce can also directly to manufacturers or publishers, inventory can be reduced, but still can not be zero inventory, Otherwise, it will be subject to too many limitations, because the demand changes very quickly; in addition, B2C e-commerce companies with their own factories in order to cope with rising costs, especially clothing companies, like Vanchem Eslite, must prepare some semi-finished products for direct secondary processing in the future At the same time, each company selling products will have dead inventory, and B2C is no exception. Therefore, it can be said that the larger the B2C, the larger the inventory, and the inventory means the occupation of funds [1].

\subsection{Website promotion.}

With the development of B2C e-commerce in recent years, the growth in sales can not be separated from the increase in user attention and media attention, and sales channels have become the key. Similar to the viral marketing of Alibaba in 2005, the Internet is flooded with advertisements of B2C websites. However, in the case of the "Tmall" family and the e-commerce homogenization, "LeFron.com" and "No.1 Some emerging B2C e-commerce companies, such as “,” and "Amoy.com," who want to gain a foothold on the Internet and share a slice of the Internet economy, must invest a lot of money for promotion. "Where the customer Eslite" has been promoted on the portal site, search engines, and even community sites. Obviously, its sales myth is 
based on funds. E-commerce can only develop if it occupies a larger market share. High-level investment does not necessarily have high output. However, without high input, there will be no high output, and there is no opportunity for low-cost expansion. Therefore, the financial environment has become the first bottleneck for the development of B2C e-commerce. Web site promotion must be supported by a large amount of funds [2].

\section{3 "First cargo after payment" mode.}

The reason why B2C shopping websites can attract users is because they have cash on delivery and free shipping discounts, and many "cash on delivery" models are collected by courier companies, so that there will be a recycling cycle for funds. There are also express payment collection fees; a considerable number of consumers will choose third-party payment tools for online payment, but even if the customer has chosen to pay online, the payment will be temporarily stored in a third-party payment tool, only after the delivery is confirmed to be paid successfully. The funds can reach the e-commerce account; with the development of credit card business, online payment has supported installment payments, but it has extended the capital turnover cycle. Therefore, the fixed settlement date plus the financial delay of third-party payment instruments not only increases the financial pressure of B2C e-commerce intangibly, but also has certain capital risks.

\subsection{Operating standby funds.}

There are many other issues that need to be considered in the operation of the B2C website. The most common ones are the large-scale promotion activities that rely on holiday concepts. These activities have given many B2C e-commerce opportunities for rapid growth. Therefore, a large amount of innovative financing will be released for promotion activities.

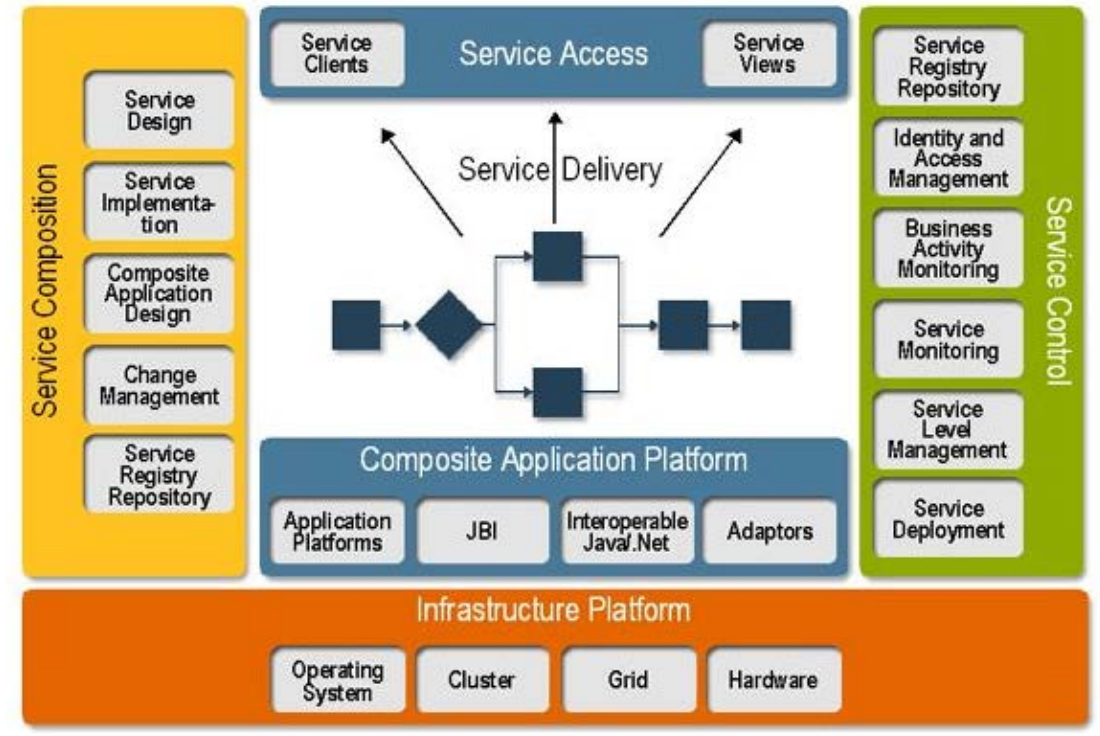

Fig.1 Supply chain structure

\section{Analysis of Supply Chain Finance Innovation Financing Model}

\subsection{Innovative financing for online orders.}

Due to the e-commerce unique distribution links, and the characteristics of third-party payment and cash on delivery, the B2C e-commerce forms a fund similar to accounts receivable. For a low inventory enterprise, the capital cost of accounts receivable It will account for a large part of operating costs. When the user submits an order on the Internet, it is a future cash flow with low risk. At this time, the $\mathrm{B} 2 \mathrm{C}$ e-commerce provider can apply for an innovative financing loan to the bank with a confirmed electronic order. The third-party payment can serve as a trading supervision platform. At present, similar businesses of domestic banks include the cooperation of China 
Construction Bank and Treasure Island e-commerce platform to launch innovative online order financing services [3].

\subsection{Innovative financing of network warehouse receipts.}

The traditional financing of warehouse receipts innovation can be subdivided into two modes: the innovative financing of holding positions and the innovative financing of financing positions. The innovative financing of guaranteed positions refers to the fact that, under the premise that the manufacturer, the core large enterprise of the industrial chain, promises repurchasing, the innovative financing enterprise will apply to the bank and use the established warehouse receipts designated by the seller in the bank as a pledge to obtain the bank loan amount. And innovative financing services subject to the bank's control of the right to take delivery of goods; financial innovation financing of finance, storage and financing is based on the assets of related companies in the supply chain stored by the third-party logistics companies, and a type of financial service that is carried out in cooperation with banks is on the supply chain. Related companies provide innovative financing services. B2C e-commerce can use the two modes flexibly according to whether it has its own factory and warehouse. Supply chain advantage score formula is as follows.

$$
S_{i}=\sum_{j=1}^{n} w_{j} p_{i j}(1 \ldots m)
$$

\section{Risks and Control Plan}

\subsection{Supply chain risk.}

The demand for B2C e-commerce market fluctuates drastically. Products and technologies have a short life cycle. Product sales are affected by factors such as sales promotion, seasonal stimulation, and holidays, making it difficult to accurately predict demand, creating a lot of confusion in the supply chain; B2C e-commerce The supply chain is dominated by small and medium-sized enterprises, the core enterprises are lacking, and the strength and credit of core companies without high business reputation are the basis. The bank's supply chain financial services will increase costs and risks; and B2C e-commerce is mainly concerned with demand. The link between cost and efficiency, when cash flow is difficult, only considers innovative financing, and the pursuit of supply chain operational efficiency and capital utilization. For the relevant stakeholders in the supply chain, there are deviations in interest. Banks need to constantly optimize the members of the industry chain, choose B2C e-commerce companies with good business performance to provide innovative financing, and B2C e-commerce itself also needs to choose large-scale suppliers as their own upstream, and at the same time, they need to take into account The benefits and risks of funding [4]. Cluster risk management plan as shown below.

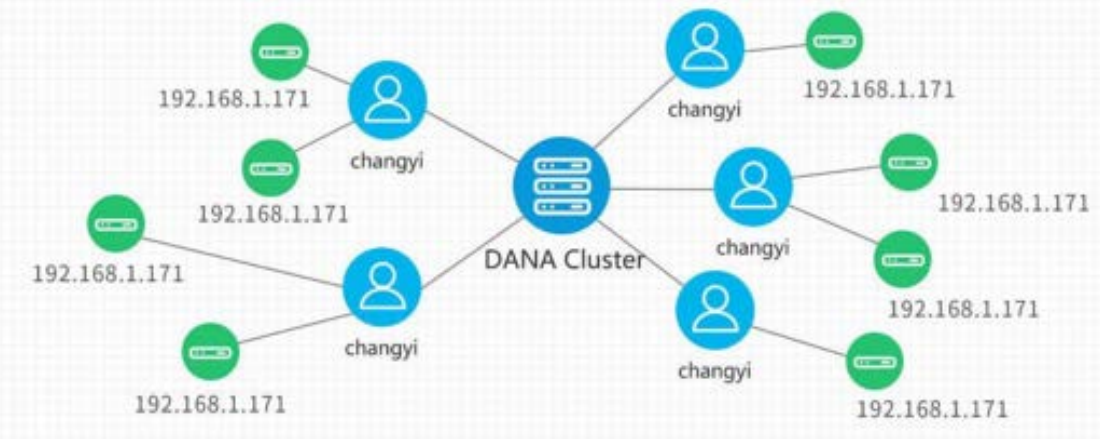

Fig.2 Cluster risk management plan

\subsection{Credit risk.}

China's current credit system has not yet formed, and supply chain management is in the initial stage of development. B2C e-commerce credit information is not effectively collected and accurately evaluated, and banks cannot independently complete the investigation and analysis of 
relevant data of all enterprises in the supply chain. Can not accurately understand the overall situation of the supply chain. At the same time, there are virtualities in the transactions on the Internet, B2C websites can use fraudulent orders to defraud bank loans, and there are also moral hazards in e-commerce guarantees.

\section{Summary}

Faced with China's currently not very mature corporate credit system and financial system, subject to funding constraints, B2C e-commerce development is uneven. In order to solve the financial pressure of B2C e-commerce, this paper proposes an innovative financing model based on B2C supply chain, and introduces the business flow of innovative financing of online orders, innovative financing of online warehouse receipts, and innovative financing of e-commerce guarantees. Through the risk analysis of applying the B2C-based supply chain innovation financing model, a risk control method is proposed. The study found that this model can not only improve the liquidity of B2C e-commerce assets, speed up the turnover of the company's trade, improve the company's operating capacity, but also help integrate and optimize capital flow, logistics and information flow, and improve the operational efficiency and value of the entire supply chain; It is conducive to the realization of bank financial service innovation and the reduction of innovative financing risks. The $\mathrm{B} 2 \mathrm{C}$ e-commerce company will operate and operate innovative collaborative management to achieve a win-win situation.

\section{References}

[1] Dongping TANG, Jingchun LEI. B2C E-Commerce Platform Competition Strategy Research Based on the Network Externality[J]. Management Science and Engineering,2016,10(2).

[2] Yingyao Shi. Analysis on the B2C E-Commerce Pattern in China[J]. Journal of Service Science and Management,2016,09(05).

[3] Erjiang E,Geng Peng, Xin Tian, Qinghong Chen, Mohammed Nouari. Online Cooperative Promotion and Cost Sharing Policy under Supply Chain Competition[J]. Mathematical Problems in Engineering,2016,2016.

[4] Shengsheng Xiao,Ming Dong. Hidden semi-Markov model-based reputation management system for online to offline (O2O) e-commerce markets[J]. Decision Support Systems,2015,77. 